\title{
Measurement of cytokine and adhesion molecule expression in synovial tissue by digital image analysis
}

\author{
M C Kraan, M D Smith, H Weedon, M J Ahern, F C Breedveld, P P Tak
}

\begin{abstract}
Objective-Digital image analysis (DIA) offers the opportunity to quantify the stained area and staining intensity when synovial tissue (ST) is investigated by immunohistochemical analysis. This study aimed at determining the sensitivity of DIA compared with semiquantitative analysis (SQA).

Methods-Paired ST samples were obtained from the knee joint of 10 patients with rheumatoid arthritis (RA) with active disease and after follow up when complete clinical remission was achieved. ST samples of 10 subjects with noninflammatory knee pain served as controls. Immunohistochemistry with antibodies against interleukin $1 \beta$ (IL1ß) and vascular cell adhesion molecule 1 (VCAM-1) was applied using two staining protocols with 3-amino-9-ethylcarbazole (AEC) or $p$-diethylaminobenzaldehyde (DAB) as dye. All sections were analysed semiquantitatively (0-4) and DIA of up to a maximum of 60 high power fields (HPF). The average integrated optical density was calculated as the product of the stained area (corrected for total tissue area) and the optical density.
\end{abstract}

Results-Both SQA and DIA enabled the assessment of differences in IL1 $\beta$ and VCAM-1 expression between ST from active RA, RA in remission, and controls. SQA and DIA showed excellent correlations (IL1 $\beta r_{\mathrm{s}}=0.867 ; \mathrm{p}<0.0001$ : VCAM-1 $\left.r_{\mathrm{s}}=0.828 ; \mathrm{p}<0.0001\right)$. A limited analysis of one region with six HPF still allowed adequate discrimination compared with an extended analysis of three regions with a total of $60 \mathrm{HPF}$. In general, the red dye (AEC) resulted in better discrimination than the brown (DAB) staining.

Conclusion-DIA offers a reliable, reproducible, and sensitive analysis of ST sections stained for cytokines and adhesion molecules.

(Ann Rheum Dis 2001;60:296-298)

In contrast with standard light microscopy, immunohistochemistry has allowed the evaluation of the expression of adhesion molecules and cytokines in synovial tissue (ST). This offered new perspectives in studies on the aetiopathogenesis and treatment of rheumatoid arthritis (RA) ${ }^{1-3}$ At present, the measurement of protein expression in ST has been performed predominantly by semiquantitative analysis (SQA). ${ }^{4}$ A possible limitation of SQA is its sensitivity to change after treatment, as documented in studies on cellular markers. ${ }^{5}$ Digital image analysis (DIA) has proved to be a sensitive and reliable tool in the evaluation of cellular markers of the infiltrate, ${ }^{67}$ and it has been applied for the measurement of cytokine and adhesion molecule expression in ST. ${ }^{8}$ In the absence of comparative studies between DIA and SQA, this study aimed at documenting the sensitivity of both techniques in the measurement of expression of cytokines and adhesion molecules in paired ST samples of patients with RA with active disease who achieved clinical remission and controls without joint inflammation.

\section{Methods}

We studied 10 patients with RA (1987 American College of Rheumatology (ACR) criteria) for expression of interleukin $1 \beta$ (IL1 $\beta$ ) and vascular cell adhesion molecule 1 (VCAM-1) in ST. In all 10 patients an arthroscopy was performed under regional anaesthesia in an actively inflamed knee joint, ${ }^{9}$ and in the same knee joint after the establishment of complete clinical remission (1981 ACR criteria ${ }^{10}$ ). ST samples were taken under direct vision with a $4.0 \mathrm{~mm}$ biopsy forceps. Controls were 10 patients who had undergone an arthroscopy for unclassified pain without signs of joint inflammation at arthroscopy and during follow up. All patients gave informed consent and the ethical committee of the Repatriation General Hospital approved the study protocol.

ST samples were either snap frozen in liquid nitrogen or fixed in formalin and subsequently embedded in paraffin. Both frozen and paraffin embedded blocks were cut in $5 \mu \mathrm{m}$ sections. Frozen sections were stained with monoclonal antibodies against VCAM-1 (anti-CD106; 1g11B1, Sanbio). Paraffin embedded sections were stained with monoclonal antibodies against IL1 $\beta$ (LP-712; Genzyme, Cambridge, MA). ${ }^{11}$ For the staining we applied a secondary and a tertiary antibody together with Fast Red (FRV, red) for IL1 $\beta$, or 3-amino-9ethylcarbazole (AEC, red) for VCAM-1, and Mayer's haemalum counterstaining. ${ }^{11}$

After staining all sections were analysed by both SQA and DIA. Two independent observers performed SQA on all sections using a five point scale. ${ }^{11}$ Three acquisition methods were used for DIA: one high power field (HPF, $\times 400$ magnification, surface $\pm 0.125 \mathrm{~mm}^{2}$ ) in six representative regions (total six $\mathrm{HPF}, 0.75 \mathrm{~mm}^{2}$ ), and 20 consecutive HPF in one representative 
Table 1 Mean score (standard error of the mean) of semiquantitative analysis (SQA) and digital image analysis (DIA) on six high power fields (HPF) and $60 \mathrm{HPF}$ for interleukin (IL) $1 \beta$ and vascular adhesion molecule (VCAM)-1. Depicted are the paired results for patients with active rheumatoid arthritis and after the achievement of clinical remission and healthy controls

\begin{tabular}{|c|c|c|c|c|c|c|}
\hline & & Active disease $(A)$ & Remission $(R)$ & Controls $(C)$ & $\begin{array}{l}A v R \\
\text { ( } p \text { value) }\end{array}$ & $\begin{array}{l}R v C \\
\text { ( } p \text { value) }\end{array}$ \\
\hline \multirow[t]{4}{*}{$\operatorname{IL} 1 \beta$} & $\begin{array}{l}\text { SQA } \\
\text { DIA }\end{array}$ & $3.0(0.3)$ & $1.4(0.3)$ & $1.0(0.2$ & $<0.005$ & NS \\
\hline & $60 \mathrm{HPF}$ & $21760(3733)$ & $10446(3034)$ & 4475 (659) & 0.005 & NS \\
\hline & $20 \mathrm{HPF}$ & 22291 (3 289) & $10506(3073)$ & $4438(713)$ & 0.005 & NS \\
\hline & $6 \mathrm{HPF}$ & 26288 (5 292) & 12996 (3 993) & $4504(741)$ & $<0.01$ & NS \\
\hline \multirow[t]{5}{*}{ VCAM-1 } & SQA & $3.1(0.4)$ & $2.2(0.4)$ & $1.0(0.3)$ & NS & $<0.05$ \\
\hline & DIA & & & & & \\
\hline & $60 \mathrm{HPF}$ & $67009(8503)$ & 39674 (9 337) & $11747(4876)$ & $<0.05$ & 0.01 \\
\hline & $20 \mathrm{HPF}$ & $68879(10458)$ & $40546(7749)$ & $11966(4534)$ & 0.01 & 0.007 \\
\hline & $6 \mathrm{HPF}$ & 83409 (12 918) & $45758(10763)$ & $10789(4494)$ & $<0.05$ & 0.005 \\
\hline
\end{tabular}
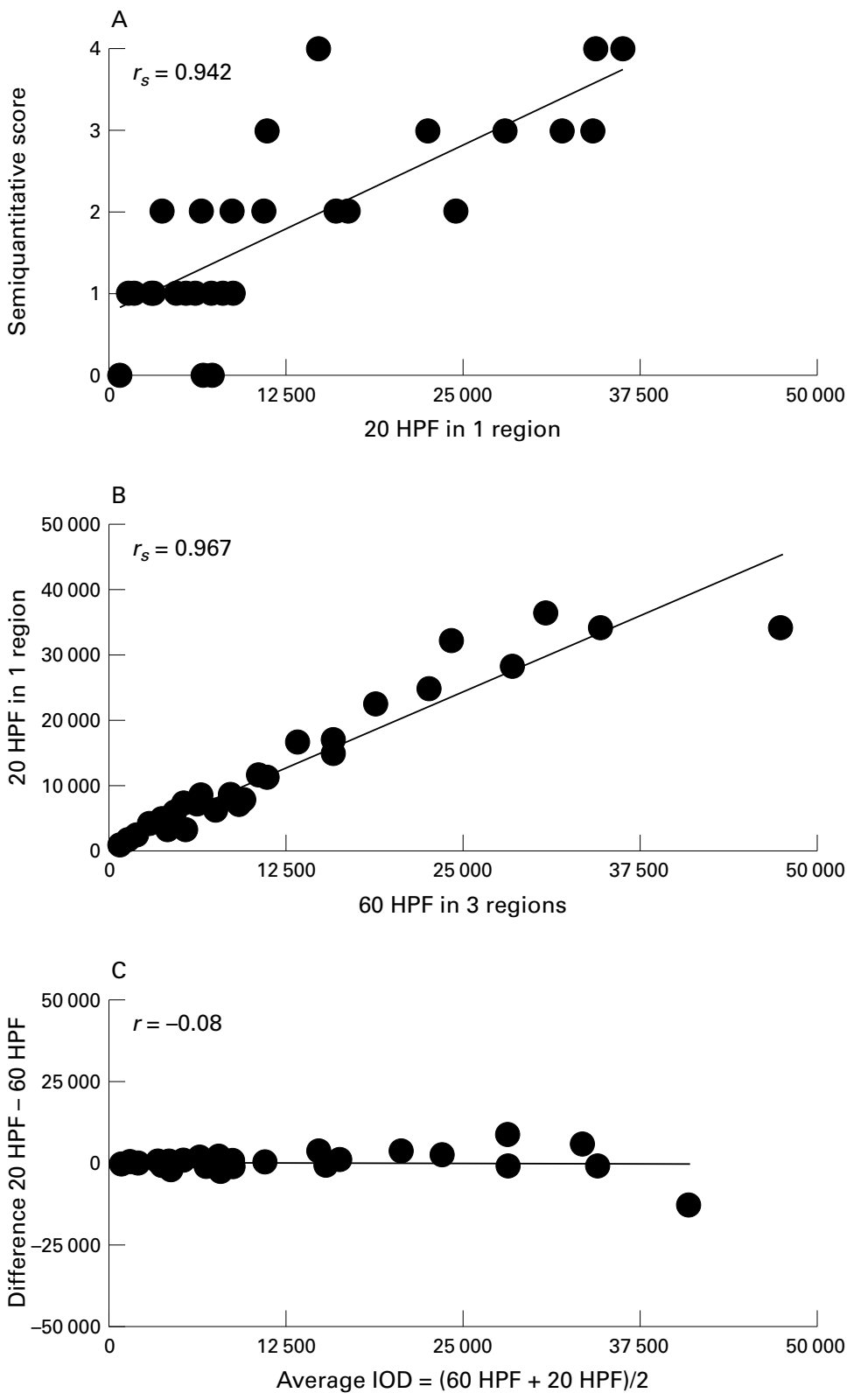

Figure 1 Plots of $(A)$ semiquantitative analysis with digital image analysis of 20 high power fields (HPF) in one single region; (B) digital image analysis of 20 high power fields (HPF) in three regions with 20 high power fields (HPF) each (total $60 \mathrm{HPF}$ ); and (C) the difference between the two digital image analyses with the average between the two techniques as suggested by Bland and Altman. ${ }^{12}$ Depicted are the semiquantitative score on a five point scale and the integrated optical density (IOD) for interleukin $1 \beta$ staining in synovial tissue of all subjects studied and the Spearman correlation coefficient $\left(r_{s}\right)$. region (total $20 \mathrm{HPF}, 2.5 \mathrm{~mm}^{2}$ ) or 20 consecutive $\mathrm{HPF}$ in three representative regions (total $60 \mathrm{HPF}, 7.5 \mathrm{~mm}^{2}$ ), respectively. ${ }^{78}$ For the analysis of all digitised images we used a specialised program written in the programming language QUIPS using the Qwin v2.2 program (Leica, Cambridge, UK) on a personal computer. We calculated the integrated optical density as the product of staining area and intensity ${ }^{8}$ corrected for the area for each section stained.

\section{STATISTICAL ANALYSIS}

Wilcoxon signed rank tests were used for the comparison of active disease and remission. Mann-Whitney tests were used to compare remission and controls. Spearman rank tests were used to calculate the correlations between the different acquisition and analysis techniques. The plot of the average and the difference of two digital image analysis procedures and the calculation of the correlation were performed as suggested by Bland and Altman. ${ }^{12}$

\section{Results}

PATIENT DEMOGRAPHICS

The mean age of the 10 patients with RA (six male, four female) was 72 years (range 59-77). Five patients had erosive disease and five patients non-erosive disease; average disease duration was 54 months (range 1-216). The mean age of the control subjects (six male, four female) was 39 years (range 28-54). None of the 10 patients with RA had taken disease modifying antirheumatic drugs at the time of the first biopsy procedure.

RESULTS OF SQA AND DIA

As shown in table 1, SQA of the sections stained for IL1 $\beta$ showed a significant difference between active disease and remission $(p<0.005)$, whereas the scores for IL1 $\beta$ were similar for patients with RA in remission and controls. DIA showed a significant difference between active disease and remission for 60 HPF ( $\mathrm{p}=0.005), 20 \mathrm{HPF}(\mathrm{p}=0.005)$, and six HPF $(p<0.01)$. Comparison of the results of DIA between patients with RA in remission and controls yielded no significant differences. SQA of the sections stained for VCAM-1 showed no significant difference between patients with active disease and patients in remission; in controls the scores were signifi- 
cantly lower $(\mathrm{p}<0.05)$. DIA showed significant differences between active disease and remission for $60 \mathrm{HPF}(\mathrm{p}<0.05), 20 \mathrm{HPF}(\mathrm{p}=0.01)$, and six HPF $(p<0.05)$. Comparison of the results of DIA between remission and controls also showed significant differences for $60 \mathrm{HPF}$ $(p=0.01), 20 \mathrm{HPF}(\mathrm{p}=0.007)$, and six HPF $(\mathrm{p}=0.005)$.

CORRELATIONS BETWEEN SQA AND DIFFERENT DIA METHODS

Figures $1 \mathrm{~A}$ and $\mathrm{B}$ show that for IL1 $\beta$, SQA was highly significantly correlated with DIA of 20 HPF $\left(r_{\mathrm{s}}=0.942, \mathrm{p}<0.0001\right)$, and $20 \mathrm{HPF}$ with $60 \mathrm{HPF}\left(r_{\mathrm{s}}=0.967, \mathrm{p}<0.0001\right)$, respectively. A strong correlation was found between $60 \mathrm{HPF}$ and $6 \mathrm{HPF}\left(r_{\mathrm{s}}=0.844, \mathrm{p}<0.0001\right)$ as well. To investigate the effect of the limitation of the number of HPF in DIA we calculated the correlation between methods of measurement. ${ }^{12}$ The calculated correlation between $60 \mathrm{HPF}$ and $20 \mathrm{HPF}$ was -0.08 , suggesting equal variance. Correlation between $60 \mathrm{HPF}$ and $6 \mathrm{HPF}$ was -0.834 , suggesting a marked difference in the variability between subjects for the two methods despite the strong correlation. Figure $1 \mathrm{C}$ shows the plot of the difference against the average of both $60 \mathrm{HPF}$ and $20 \mathrm{HPF}$. Similar results were found for VCAM-1.

\section{Discussion}

In this study we show that DIA and SQA give similar results for the analysis of both IL $1 \beta$ and VCAM expression in ST sections. Overall, DIA proved to be slightly more sensitive, especially in comparing remission with controls. Moreover, even a limited analysis of $20 \mathrm{HPF}$ (or $2.5 \mathrm{~mm}^{2}$ of $\mathrm{ST}$ ) produced representative results.

To our knowledge this is the first paper comparing SQA with DIA for the analysis of cytokine and adhesion molecule expression in the synovial tissue of patients with RA. We chose to investigate the expression of IL $1 \beta$ in synovial tissue because this cytokine plays a part in both inflammation and destruction. Furthermore, it has been documented that joint destruction associated with RA can be found in patients in clinical remission and we expected this cytokine to be of special interest in our study group. ${ }^{13}$ DIA identified differences between controls and patients with RA in remission, but these changes were not statistically significant.

We investigated VCAM-1 based upon the role of the VCAM-1/VLA-4 ligand pair in the preferential recruitment of activated lymphocytes and monocytes from the circulation into the RA ST. ${ }^{14}$ Of interest, we noted an increased expression of VCAM-1 in patients with RA in remission. This observation is consistent with previous observations showing signs of activation in clinically unaffected joints. ${ }^{15}$

We conclude that the ability of DIA to quantify the expression of a marker offers a sensitive tool to determine protein expression in synovial tissue. Because it can be expected that DIA will be increasingly used for the evaluation of synovial tissue, further standardisation of the methodology is mandatory.

1 Yanni G, Whelan A, Feighery C, Quinlan W, Symons J, Duff $\mathrm{G}$, et al. Contrasting levels of in vitro cytokine production by rheumatoid synovial tissues demonstrating different patterns of mononuclear cell infiltration. Clin Exp mmunol 1993;93:387-95.

2 Tak PP, Taylor PC, Breedveld FC, Smeets TJM, Kluin PM, Meinders AE, et al. Reduction in cellularity and expression of adhesion molecules in rheumatoid synovial tissue after anti-TNF-alfa monoclonal antibody treatment. Arthritis Rheum 1996;39:1077-81.

3 Edwards JC, Wilkinson LS, Speight P, Isenberg DA. Vascuar cell adhesion molecule 1 and alpha 4 and beta 1 integrins in lymphocyte aggregates in Sjögren's syndrome and rheumatoid arthritis. Ann Rheum Dis 1993:52:80611 .

4 Smeets TJM, Kraan MC, Versendaal H, Huizinga TWJ, Breedveld FC, Tak PP. Analysis of serial biopsies in RA patients: description of a control group without clinical improvement after treatment with RhuIL-10 or placebo. J improvement after treatment with

5 Youssef PP, Smeets TJM, Bresnihan B, Cunnane G, FitzGerald O, Breedveld FC, et al. Microscopic measurement of inflammation in the rheumatoid arthritis synovial membrane: a comparison of semiquantiative and quantitative analysis. Br J Rheumatol 1998;37:1003-7.

6 Cunnane G, Bjork L, Ulfgren AK, Lindblad S, FitzGerald $\mathrm{O}$, Bresnihan $\mathrm{B}$, et al. Quantitative analysis of synovial membrane inflammation: a comparison between automated and conventional microscopic measurements. Ann Rheum Dis 1999;58:493-9.

7 Kraan MC, Haringman JJ, Ahern MJ, Breedveld FC, Smith $\mathrm{MD}$, Tak PP. Quantification of the cell infiltrate in synovial tissue by digital image analysis. Rheumatology 2000;39: 43-9.

8 Youssef PP, Triantafillou S, Parker A, Coleman M, RobertsThomson P, Ahern MJ, et al. Variability in cytokine and cell adhesion molecule staining in arthroscopic synovial biopsies: quantification using color video image analysis. J biopsies: quantification using

9 Smith MD, Chandran G, Youssef PP, Darby T, Ahern MJ. Day case knee arthroscopy under regional anaesthesia, performed by rheumatologists. Aust N Z J Med 1996;26: $108-9$.

10 Pinals RS, Masi AT, Larsen RA, Subcommittee for the criteria of remission in rheumatoid arthritis of the ACR diagnostic and therapeutic criteria committe. Preliminary criteria for clinical remission in rheumatoid arthritis. Arthritis Rheum 1981;24:1308-15.

11 Tak PP, van der Lubbe A, Cauli A, Daha MR, Smeets TJM, Kluin PM, et al. Reduction of synovial inflammation after anti-CD4 monoclonal antibody treatment in early rheumatoid arthritis. Arthritis Rheum 1995;38:1457-65.

12 Bland JM, Altman DG. Comparing methods of measurement: why plotting difference against standard measurement: why plotting difference against
method is misleading. Lancet 1996;346:1085-7.

13 Mulherin D, FitzGerald O, Bresnihan B. Clinical improvement and radiological deterioration in rheumatoid arthritis: evidence that the pathogenesis of synovial inflammation and articular erosion may differ. Br J Rheumatol 1996;35:1263-8.

4 van Dinther-Janssen AC, Horst E, Koopman G, Newmann W, Scheper RJ, Meijer CJ, et al. The VLA-4/VCAM-1 pathway is involved in lymphocyte adhesion to endothelium in rheumatoid synovium. J Immunol 1991;147:420710 .

15 Kraan MC, Versendaal H, Jonker M, Bresnihan B, Post W, manifest arthritis. Arthritis Rheum 1998;41:1481-8. 